\title{
A Novel Dimeric Dipeptide Mimetic of the Nerve Growth Factor Exhibits Pharmacological Effects upon Systemic Administration and Has No Side Effects Accompanying the Neurotrophin Treatment
}

\author{
T. A. Gudasheva ${ }^{1}$, P. Yu. Povarnina1, T. A. Antipova' ${ }^{2}$, S. B. Seredenin ${ }^{3}$ \\ ${ }^{1}$ Department of Medicinal Chemistry, Zakusov Institute of Pharmacology, Russian Academy of Medical Sciences, \\ Moscow, Russia \\ ${ }^{2}$ Laboratory of Pharmacology of Neuroprotection, Zakusov Institute of Pharmacology, Russian Academy of \\ Medical Sciences, Moscow, Russia \\ ${ }^{3}$ Department of Pharmacogenetics, Zakusov Institute of Pharmacology, Russian Academy of Medical Sciences, \\ Moscow, Russia \\ Email: "tata-sosnovka@mail.ru
}

Received 1 March 2014; revised 30 March 2014; accepted 20 April 2014

Copyright $@ 2014$ by authors and Scientific Research Publishing Inc.

This work is licensed under the Creative Commons Attribution International License (CC BY).

http://creativecommons.org/licenses/by/4.0/

(c) (i) Open Access

\section{Abstract}

The development of small molecule nerve growth factor (NGF) mimetics is a promising approach to overcome limitations in the use of the neurotrophin as a drug, which are poor pharmacokinetics and undesirable side effects. We designed dimeric dipeptide called GK-2 (bis(N-succinyl-Lglutamyl-L-lysine)hexametylendiamide) on the base of beta-turn sequence of NGF loop4 which most exposed to solvent and hence can play the major role in the interaction of NGF with the receptor. It was shown, that GK-2 stimulates phosphorylation of TrkA receptor, selectively activates PI3K/Akt signaling cascade that is important for cell survival, and does not activate MAPK/Erk pathway, associated not only with cell survival but also with cell differentiation. According to these data, GK-2 in vitro prevented $\mathrm{H}_{2} \mathrm{O}_{2}$ - or MPTP- or glutamate-induced neuronal cell death at nanomolar concentrations, but did not provoke neurite outgrowth in PC12 cells. In vivo GK-2 exhibits therapeutic effects in models of Parkinson's disease, Alzheimer's disease, brain ischemia and diabetes mellitus. GK-2 shows activity in doses $0.01-5 \mathrm{mg} / \mathrm{kg}$ intraperitoneally and retains the activity after oral administration in dose $10 \mathrm{mg} / \mathrm{kg}$. GK-2 has no side effects accompanying NGF treatment namely hyperalgesia and weight loss. Thus, the designed dimeric substituted dipeptide

\footnotetext{
"Corresponding author.
} 
provides promising drug candidate and a molecular tool for investigating the possibility of divergence in NGF therapeutic and adverse effects.

\title{
Keywords
}

\author{
Nerve Growth Factor, Mimetic, Dipeptide, GK-2, TrkA, PI3K/Akt, MAPK/Erk, Alzheimer's Disease, \\ Parkinson's Disease, Stroke, Diabetes
}

\section{Introduction}

Nerve growth factor (NGF) has gained much attention as a potential therapeutic agent for a number of disorders ranging from neurodegenerative diseases to inflammation, glaucoma and diabetes mellitus. Despite a success in a multitude of preclinical studies, the results of the majority of NGF clinical trials have been disappointing [1]. The pharmacological use of NGF is limited by its poor pharmacokinetics and undesirable side effects such as hyperalgesia and severe weight loss. A possible strategy to overcome these limitations is to develop low-molecular agents which would mimic the therapeutic effects of NGF during systemic administration while having no adverse effects. Several molecules mimicking specific neurotrophin signalings have been reported as potential therapeutic agents to overcome limitations of the native protein [2]-[6].

\section{Design and Synthesis of Dimeric Dipeptide Mimetic of NGF}

To mimic NGF functions pharmacologically, we designed a dimeric dipeptide called GK-2 (bis(N-succinyl-Lglutamyl-L-lysine)hexametylendiamide) on the basis of a beta-turn sequence of Asp ${ }^{93}$-Glu ${ }^{94}$-Lys ${ }^{95}$ of loop 4 which is most exposed to solvent and hence can play a major role in the NGF-receptor interaction. The designed mimetic was synthesized by the methods of classical peptide synthesis in solution including the techniques of activated esters and with the use of the strategy of Boc/Z protecting groups. The Asp ${ }^{93}$ residue was substituted for by bioisostere, a succinic acid residue. This substitution might increase in the resistance of the molecules to proteolysis. Since NGF interacts with the TrkA receptor in the dimeric form, the agonistic activity was achievied by dimerizing of $\mathrm{N}$-acyldipeptide by hexametylenediamine [7] [8].

\section{In Vitro Studies}

NGF exerts its effects via two transmembrane receptors, TrkA (tropomyosin receptor kinase A) and p75NTR. Activation of TrkA promotes neuronal survival and differentiation. These effects are mediated by two main intracellular signaling cascades, PI3K/Akt and MAPK/Erk. The activation of the first pathway is important for cell survival, whereas the MAPK/Erk activation is mainly associated with cell differentiation [9]. The latter is also essential for the induction of hyperalgesia [10]. The P75 receptors regulate signaling throw TrkA or, in the absence of TrkA, they can induce apoptosis.

We have examined possible neuroprotective and differentiative activity of GK-2 and ability of this dipeptide to induce the activation of TrkA receptors and PI3K/Akt and MAPK/Erk signaling pathways.

\subsection{GK-2 Demonstrates NGF-Like Neuroprotective, but Not Differentiative, Activity}

Experiments on the culture of immortalized mouse hippocampal neurons (line HT-22), primary culture of rat hippocampal neurons ( $\mathrm{HN}$ ) and dopamine-positive PC-12 cells of rat pheochromacytoma were performed. For evaluation of the GK-2 neuroprotective effect, the peptide was added $24 \mathrm{~h}$ before the cells were exposed to damage factors: $\mathrm{H}_{2} \mathrm{O}_{2}(1.5 \mathrm{mM})$, or MPTP $(1 \mathrm{mM})$, or glutamate $(5 \mathrm{mM})$. NGF in a final concentration of 100 $\mathrm{ng} / \mathrm{ml}$ was used as a positive control. Cell viability was measured $24 \mathrm{~h}$ after the toxin addition in the test with 3-(4,5-dimethylthiazol-2-yl)-2,5-diphenyltetrazolium bromide (MTT). Optical density was measured on a Multiscan EX spectrophotometer. GK-2 in a concentration of up to $10^{-9} \mathrm{M}$ produced a protective effect on the culture of immortalized cells and primary neurons after the addition of $\mathrm{H}_{2} \mathrm{O}_{2}$ and glutamate, and in a concentration of up to $10^{-8} \mathrm{M}$, it protected PC-12 cells from the MPTP neurotoxin. The activity of GK-2 was similar to that of NGF [11]. To determine differentiating properties of GK-2, we used PC-12 cells that can undergo differentiation 
of the neuronal type after the addition of NGF. GK-2 did not provoke neurite outgrowth in PC-12 cells [7]. Therefore, GK-2 showed a high neuroprotective, but not differentiative activity.

\subsection{GK-2 Activates TrkA Receptor and Stimulates Synthesis of Heat Shock Proteins Hsp32 and Hsp70}

To investigate the interaction of the dipeptide GK-2 with TrkA, we examined its effect on the phosphorylation of tyrosine kinase A in the cytoplasmic fraction of HT-22 neurons by Western blot analyses. It was established that GK-2 in a concentration of $10^{-8} \mathrm{M}$ increases the phosphorylation of TrkA [7].

The mechanisms of neuroprotective effects of NGF comprise the increase in the levels of the HSP70 and HSP32 heat-shock proteins. It was shown than GK-2, similarly to NGF, increases the content of Hsp32 and Hsp70 in the cytoplasmic fraction of immortalized mouse hippocampal HT22 neurons [7].

\subsection{GK-2 Activates PI3K/Akt, but Not MAP/Erk Signaling Pathway}

HT-22 cells were exposed to GK-2 $\left(10^{-6} \mathrm{M}\right)$ or NGF $(100 \mathrm{ng} / \mathrm{ml})$. Biochemical assays included Western blot analyses of the Akt and Erk phosphorylation at different time points. The phosphorylation of Akt was observed 15, 30, 60 and 180 min after the cell stimulations by GK-2, or 15, 60 and 180 min after the stimulation by NGF. Furthermore, the NGF-induced phosphorylation of Erk after 60 and 180 min was observed. At the same time, there was no activation of the Erk proteins by GK-2 at any time point [12]. In addition, it was shown that LY294002, a PI3 kinase inhibitor, but not PD9859, a MAP kinase inhibitor, abolishes neuroprotective effects of GK-2 in vitro.

It is known that the PI3K/Akt pathway activation is important for cell survival, whereas MAPK/Erk activation is not only associated with cell survival, but also with cell differentiation and is involved in the induction of hyperalgesia [10].

\section{In Vivo Studies}

In order to test the ability of GK-2 to mimic the in vivo therapeutic properties of NGF, we investigated the activity of the dipeptide on animal models with Parkinson's disease (PD), Alzheimer's disease (AD), focal and global brain ischemia and diabetes mellitus. In addition, we examined a possible capacity of GK-2 to induce hyperalgesia or weight loss in rats.

\subsection{Antiparkinsonian Properties of GK-2}

Numerous evidences that the NGF deregulations are connected with Parkinson's diseases occur. NGF concentration is decreased in the substantia nigra in parkinsonian patients [13]. NGF rescues nigral dopaminergic neurons and restores functional deficits in rats with unilateral 6-hydroxydopamine lesion [14]. NGF adsorbed on poly (butylcyanoacrylate) nanoparticles significantly decreases the MPTP-induced Parkinson's syndrome in mice [15].

We studied the antiparkinsonian properties of GK-2 on the following models: haloperidol-induced catalepsia in rats, MPTP-induced parkinsonism in mice and striatal 6-OHDA lesion in rats.

\subsubsection{GK-2 Reverses Haloperidol-Induced Catalepsy in Rats}

Male white outbred rats were used in the study. GK-2 was administered by a single injection $24 \mathrm{~h}$ before haloperidol. It was shown that this dipeptide significantly (by $80 \%$ - 90\%) reverses haloperidol-induced catalepsy, at least in doses from 0.01 to $5 \mathrm{mg} / \mathrm{kg}$ intraperitoneally (i.p.) and retains the activity after oral administration in a dose of $10 \mathrm{mg} / \mathrm{kg}$. Experiments with various time regimes of GK-2 treatment (48, 24, 16, $1 \mathrm{~h}$ before and 30 and 45 min after the haloperidol injection) showed that this agent exhibits anticataleptic activity under the conditions of administration $24 \mathrm{~h}$ before or $45 \mathrm{~min}$ after the haloperidol injection [16].

\subsubsection{GK-2 Rescues Motor Deficits in MPTP-Induced Parkinsonism in Mice}

Male C57Bl/6 mice were used. Parkinsonian syndrome was induced by a single or repeated injections of MPTP. Acute injection of GK-2 (1 mg/kg, i.p.) 24 h prior to the MPTP administration (35 mg/kg, i.p.) reduced the manifestation of oligokinesia ( $90 \mathrm{~min}$ and 7 days after MPTP) and rigidity (21 days after MPTP) in mice. Subchronic 
administration of GK-2 (1 mg/kg, i.p.) after MPTP (15 mg/kg, i.p. with 2 h intervals, to a total of 4 times) completely abolished rigidity in mice by the 14th post-lesion day [16].

\subsubsection{GK-2 Totally Abolishes Apomorphine-Induced Rotations in Unilateral 6-Hydroxydopamine-Lesioned Rats}

Male white outbred rats were subjected to stereotaxic unilateral intrastriatal injection of 6-OHDA. GK-2 (1 $\mathrm{mg} / \mathrm{kg}$, i.p.) was administered $1 \mathrm{~h}$ after lesion followed by 7 more injections performed every $48 \mathrm{~h}$. On the 16th day after surgery, the apomorphine-induced turning behavior was registered during a 20-min period. Sham animals showed no turning behavior. At the same time, marked contralateral rotations were observed in rats with striatal lesions. GK-2 almost completely abolished this turning behavior [16].

\subsection{GK-2 Prevents Neuronal Damage, Neurological and Cognitive Decline in Rat Models of Cerebral Ischemia}

The neuroprotective potential of NGF against ischemic brain damage is well studied. In experimental brain ischemia, NGF mRNA expression and NGF protein content is upregulated transiently and this seems to be protective for neurons [17] [18]. It is well established that an enhancement of NGF concentration in cerebrospinal fluid of patients with stroke on the 1st day is accompanied by a smaller cerebral infarction size on the 5 - 7th day, better survival and less disability (using comparable vascular lesion localizations and sizes of the ischemic zone) [19]. Intraventricular infusion of NGF in different rodent models of cerebral ischemia resulted in a significant brain protection [20]-[22].

We investigated GK-2 activity in models of both focal and global cerebral ischemia.

\subsubsection{Neuroprotective and Antiamnestic Effects of GK-2 in Experimental Ischemic Infarction of Brain Cortex}

Experiments were carried out on outbred male rats. Bilateral focal ischemic stroke of the prefrontal cortex was created by photoinduced thrombosis. GK-2 was injected (1 mg/kg, i.p.) $1 \mathrm{~h}$ after the operation, then $24 \mathrm{~h}$ after the first injection, and on the 4th and 6th days after the first injection. Passive avoidance was trained in all experimental animals before the operation (latency $>300 \mathrm{sec}$ ). After photothrombosis, the latency of entry into the dark compartment decreased from 300 to 59.2 sec. The reflex was completely retained in animals treated with GK-2; the passive avoidance latency in these animals was equal to or longer than $300 \mathrm{sec}$. Morphometric measurements showed that the GK-2 treatment decreased in the total volume of the cerebral injury by $60 \%$ [23].

\subsubsection{GK-2 Reduces Infarction Volume and Neurological Deficits Following Focal Ischemia Induced by Middle Cerebral Artery Occlusion}

Experiments were carried out on outbred male rats. The animals were subjected to transient unilateral intravascular occlusion of the middle cerebral artery with a silicone-covered nylon. After a 60 -min occlusion, the thread was removed to restore circulation in the basin of the middle cerebral artery. GK-2 (1 mg/kg, i.p.) was injected after the lesion daily for 6 days. Under these conditions, GK-2 significantly improved neurological deficits scored in the limb-stimulation test and in the cylinder test on the 7th day after lesion. MRI-study showed that GK-2 treatment reduced the infarction area by on average $16 \%$ [24].

\subsubsection{GK-2 Exerts Neuroprotective Effects and Restores Cognitive Deficits in a Model of Incomplete Global Cerebral Ischemia}

Male white outbred rats were used. Incomplete global cerebral ischemia was induced by permanent common carotide artery occlusion. GK-2 (0.5 mg/kg, i.p.) was injected $4 \mathrm{~h}$ after the surgery followed by 7 more injections performed every 24 hours. On the 8th and 9th days after the lesion, the exploratory behavior of rats was examined in open field test and novel object exploration test [25]. A half of animals from each group were sacrificed by decapitation 16 days after surgery. Cerebral cortex, striatum and hippocampus were separated to estimate cell viability by the MTT-assay. The remaining animals underwent the object recognition test 3.5 months after the surgery. GK-2 treatment fully prevented the deaths in lesioned rats and completely restored cerebral cortex cells viability that decreased as a result of the common carotide artery occlusion. GK-2 prevented the development of habituation deficits (open field test), decreased in the exploratory activity (novel object test) on the 
8th - 9th days after the surgery and reversed working memory deficits (object recognition test) 3.5 months after the surgery [26].

4.2.4. GK-2 Reduces Neural Degeneration and Improves Neurological Deficits after Cardiac Arrest Male white outbred rats were subjected to cardiac arrest for $12 \mathrm{~min}$ followed by resuscitation. GK-2 (1 mg/kg, i.p.) was injected $30 \mathrm{~min}$ and then $48 \mathrm{~h}$ after resuscitation. It was found out that GK-2 reduces neuronal dystrophic changes and death in the pyramidal neurons of the hippocampal CA1 sector and in the cerebellar Purkinje cells on the 7th postresuscination day [27]. On the 14th resuscination day, GK-2 completely rescued the hippocampal pyramidal neurons. In addition, GK-2 accelerated the neurological recovery of the resuscinated rats.

\subsection{GK-2 Recues Cognitive Decline in Rat Models of Alzheimer's Disease}

High therapeutic potential of NGF for Alzheimer's disease (AD) treatment is well known. The progressive decline in cognitive functions in $\mathrm{AD}$ patients is associated with the degeneration of cholinergic neurons that are highly dependent on the viability of NGF. In addition, NGF was described as a direct anti-amyloidogenic factor [28]. In animal models of AD, NGF prevents the death of cholinergic neurons and improves learning and memory in lesioned and aged animals [29]-[32].

To study effects of GK-2, we used the following approaches: fimbria/fornix transsection; experimental AD induced by intracerebroventricular injection of streptozotocine and a model of cognitive deficits induced by chronic administration of scopolamine.

\subsubsection{GK-2 Restores Habituation Deficits Following Transsection of Fimbria/Fornix}

Male Wistar rats were subjected to cholinergic denervation of the hippocampus by bilateral fimbria/fornix transsection. GK-2 (1 mg/kg, i.p.) was injected $2 \mathrm{~h}$ after surgery followed by 6 more injections performed every $48 \mathrm{~h}$. On the 15th days after surgery, the exploratory behavior of rats was examined in an open field test. Sham animals demonstrated a reduction in exploratory horizontal motor activity during the test (it might be defined as spatial habituation learning). Fimbria/fornix lesion caused significant habituation deficits, which manifested in almost unchanged level of horizontal motor activity. The habituation behavior in GK-2-treated rats was restored [33].

\subsubsection{GK-2 Reverses Intracerebroventricular Streptozotocine-Induced Cognitive Deficits}

Male white outbred rats were used in the investigation. Experimental model of AD was established by bilateral intracerebroventricular injection of streptozotocin $(3 \mathrm{mg} / \mathrm{kg}$ ). The Morris water maze test was performed on the 21st - 25th (training trials) and 32 (test trial) days to assess learning and memory of the animals. GK-2 was administered during 14 days after lesion $(0.5 \mathrm{mg} / \mathrm{kg}$, i.p., every $24 \mathrm{~h})$. The streptozotocin-treated were significantly impaired as compared to sham rats operated in learning which was measured by a latency to locate of a submerged platform across days of training. GK-2 significantly reduced these spatial learning impairments [33].

\subsubsection{GK-2 Attenuates Scopolamine-Induced Spatial Learning Impairments in Rats}

Male white outbred rats received daily injections of a muscarinic receptor blocker, scopolamine $(1 \mathrm{mg} / \mathrm{kg}$, i.p.) during 20 days. After the scopolamine treatment, the rats received daily injections of GK-2 (0.2; 0.5 or $2 \mathrm{mg} / \mathrm{kg}$, i.p.) for 10 days. The animals were then tested in the Morris water maze across 4 days with 3 days of acquisition trials and a single probe trial on the 4th day. Scopolamine-treated rats were significantly impaired in comparison with the control animals in learning the location of the submerged platform which was measured by the latency to locate. GK-2 almost completely reversed this impairment.

\subsection{GK-2 Exhibits Antihyperglycemic Properties in Streptozotocine-Diabetic Rats}

The therapeutic potential of NGF in the treatment of diabetes mellitus is coming from its trophic functions towards pancreatic beta cells. NGF plays an important role in the differentiation and maintenance of beta cells [34]. Beta cells synthesize and secrete NGF, which stimulates the insulin release through autocrine regulation; synthesis and secretion of NGF by beta cells are increased in response to an elevation of extracellular glucose concentration [35]. A slowdown of the beta cells proliferation in diabetes is caused, in particular, by deficits of 
neurotrophic factors [36].

The study was performed in male Wistar rats. Diabetes was induced in them by a single i.p. injection of streptozotocin (STZ) in a dose of $40 \mathrm{mg} / \mathrm{kg}$. GK-2 was administered daily for 14 days before and 28 days after the STZ injection. Straight before the STZ injection and on the 3rd, 17th and 28th day after it, blood samples were taken from the tail vein and glucose levels were determined using an automated glucose analyzer (One Touch Ultra, USA). Diabetes resulted in marked hyperglycemia and progressive body weight loss in comparison with control animals. GK-2 completely reversed the body weight loss. Blood glucose concentration already increased significantly in STZ-injected rats on the 3rd day and remained on a greater than $15 \mathrm{mmol} / \mathrm{l}$ level during the experiment. GK-2 significantly decreased blood glucose concentration across all time points with the maximal therapeutic effect of about $80 \%$ on the 28 th day.

\subsection{GK-2 Does Not Exert Adverse Effects Characteristic of NGF Treatment}

Pain and weight loss are two main undesired adverse effects that limit the clinical application of NGF. We have suggested that GK-2 would not have such effects, because GK-2 selectively activates PI3K/Akt signaling pathway that is essential for cells survival. Influence of GK-2 on pain sensitivity and body weight was examined.

\subsubsection{GK-2 Does Not Induce Pain Hypersensitivity}

GK-2 (0.5 - $2 \mathrm{mg} / \mathrm{kg}$, i.p.) was administered to outbred male rats. A possible effect of the GK-2 dipeptide on pain sensitivity was examined in tail flick test $30 \mathrm{~min}, 60 \mathrm{~min}$ and $24 \mathrm{~h}$ after the dipeptide injection. These time intervals were chosen in accordance with peaks of NGF-induced hyperalgesia [37]. It was established that GK-2 does not reduce the pain threshold in the tail flick test at all time points.

\subsubsection{GK-2 Does Not Induce Weight Loss}

Male white outbred rats were used. GK-2 $(0.5 \mathrm{mg} / \mathrm{kg}$, i.p.) was administered daily during 2 weeks. Control rats were treated with a vehicle (distilled water). No effect of GK-2 on the body weight was visible.

\subsection{Acute Toxicity of GK-2}

Male and female white outbred mice were used for the toxicity study. GK-2 was administered as a single i.p. infusion. The $\mathrm{LD}_{50}$ values of GK-2 were $713.7 \mathrm{mg} / \mathrm{kg}$ in male and $668.3 \mathrm{mg} / \mathrm{kg}$ in female mice. The drug can therefore be characterized as a low-toxicity compound. Further observations showed that the surviving animals returned to normal condition and behavior within $24 \mathrm{~h}$.

\subsection{Pharmacokinetics of GK-2}

Male white outbred rats were used. The quantitative analysis of blood and brain samples was performed by a high-sensitive HPLC/MS method. It was established that the unchanged compound could be detected in the blood during 20 min after the i.p. administration, and it crossed the blood-brain barrier.

\section{Conclusions}

In sum, a dimeric dipeptide mimetic of NGF GK-2 interacts with TrkA receptors and selectively activates PI3K/ Akt signaling pathway. GK-2 has a high neuroprotective, but not differentiative, in vitro activity and reproduces NGF-like pharmacotherapeutic effects on animal models of Parkinson's disease, Alzheimer's disease, brain ischemia and diabetes mellitus. It is important to note that GK-2 does not induce pain hypersensitivity and weight loss that are the main undesirable side effects associated with the NGF treatment.

Thus, the GK-2 dipeptide offers hope as a potential NGF-like therapeutic agent.

\section{References}

[1] Aloe, L., Rocco, M.L., Bianchi, P. and Manni, L. (2012) Nerve Growth Factor: From the Early Discoveries to the Potential Clinical Use. Journal of Translational Medicine, 10, 239-252. http://dx.doi.org/10.1186/1479-5876-10-239

[2] Longo, F.M., Manthorpe, M., Xie, Y.M. and Varon, S. (1997) Synthetic NGF Peptide Derivatives Prevent Neuronal Death via a P75 Receptor-Dependent Mechanism. Synthetic NGF Peptide Derivatives Prevent Neuronal Death via a P75 Receptor-Dependent Mechanism. Journal of Neuroscience Research, 48, 1-17. 
http://dx.doi.org/10.1002/(SICI)1097-4547(19970401)48:1<1::AID-JNR1>3.0.CO;2-K

[3] Peleshok, J. and Saragovi, H.U. (2006) Functional Mimetics of Neurotrophins and Their Receptors. Biochemical Society Transaction, 34, 612-617. http://dx.doi.org/10.1042/BST0340612

[4] Massa, S.M., Yang, T., Xie, Y., Shi, J., Bilgen, M., Joyce, J.N., Nehama, D., Rajadas, J. and Longo, F.M. (2010) Small Molecule BDNF Mimetics Activate TrkB Signaling and Prevent Neuronal Degeneration in Rodents. The Journal of clinical investigation, 120, 1775-1785. http://dx.doi.org/10.1172/JCI41356

[5] Colangelo, A.M., Bianco, M.R., Vitagliano, L., Cavaliere, C., Cirillo, G., De Gioia, L., Diana, D., Colombo, D., Redaelli, C., Zaccaro, L., Morelli, G., Papa, M., Sarmientos, P., Alberghina, L. and Martegani, E. (2008) A New Nerve Growth Factor-Mimetic Peptide Active on Neuropathic Pain in Rats. The Journal of Neuroscience, 10, 2698-2709. http://dx.doi.org/10.1523/JNEUROSCI.1508-04.2004

[6] Scarpi, D., Cirelli, D., Matrone, C., Castronovo, G., Rosini, P., Occhiato, E.G., Romano, F., Bartali, L., Clemente, A.M., Bottegoni, G., Cavalli, A., De Chiara, G., Bonini, P., Calissano, P., Palamara, A.T., Garaci, E., Torcia, M.G., Guarna, A. and Cozzolino, F. (2012) Low Molecular Weight, Non-Peptidic Agonists of TrkA Receptor with NGFMimetic Activity. Cell Death and Disease, 3, 389-402. http://dx.doi.org/10.1038/cddis.2012.80

[7] Gudasheva, T.A., Antipova, T.A. and Seredenin, S.B. (2010) Novel Low-Molecular-Weight Mimetics of the Nerve Growth Factor. Doklady Biochemistry and Biophysics, 434, 262-265. http://dx.doi.org/10.1134/S160767291005011X

[8] Seredenin, S.B. and Gudasheva, T.A. (2011) Dipeptide Mimetics of NGF and BDNF Neurotrophins. US Patent, Application No. US 2011/0312895 A1.

[9] Reichardt, L.F. (2006) Neurotrophin-Regulated Signalling Pathways. Philosophical Transactions of the Royal Society of London, Series B: Biological Sciences, 361, 1545-1564. http://dx.doi.org/10.1098/rstb.2006.1894

[10] Obata, K. and Noguchi, K. (2004) MAPK Activation in Nociceptive Neurons and Pain Hypersensitivity. Life Sciences, 74, 2643-5263. http://dx.doi.org/10.1016/j.lfs.2004.01.007

[11] Antipova, T.A., Gudasheva, T.A. and Seredenin, S.B. (2011) In Vitro Study of Neuroprotective Properties of GK-2, a New Original Nerve Growth Factor Mimetic. Bulletin of Experimental Biology and Medicine, 150, 607-609. http://dx.doi.org/10.1007/s10517-011-1202-6

[12] Gudasheva, T., Antipova, T., Povarnina, P. and Seredenin, S. (2013) NGF Loop 4 Dimeric Dipeptide Mimetic Active on Animal Models of Parkinson's, Alzheimer's Diseases and Stroke. Proceedings of the 23rd American and the 6th International Peptide Symposium, Big Island, 22-27 June 2013, 194-195.

[13] Mogi, M., Togari, A., Kondo, T., Mizuno, Y., Komure, O., Kuno, S., Ichinose, H. and Nagatsu, T. (1999) Brain-Derived Growth Factor and Nerve Growth Factor Concentrations are Decreased in the Substantia Nigra in Parkinson's Disease. Neuroscience Letters, 270, 45-48. http://dx.doi.org/10.1016/S0304-3940(99)00463-2

[14] Chaturvedi, R.K., Shukla, S., Seth, K. and Agrawal, A.K. (2006) Nerve Growth Factor Increases Survival of Dopaminergic Graft, Rescue Nigral Dopaminergic Neurons and Restores Functional Deficits in Rat Model of Parkinson’s Disease. Neuroscience Letters, 398, 44-49. http://dx.doi.org/10.1016/j.neulet.2005.12.042

[15] Kurakhmaeva, K.B., Voronina, T.A., Kapica, I.G., Kreuter, J., Nerobkova, L.N., Seredenin, S.B., Balabanian, V.Y. and Alyautdin R.N. (2008) Antiparkinsonian Effect of Nerve Growth Factor Adsorbed on Polybutylcyanoacrylate Nanoparticles Coated With Polysorbate-80. Bulletin of Experimental Biology and Medicine, 145, 259-262. http://dx.doi.org/10.1007/s10517-008-0065-y

[16] Povarnina, P.Y., Gudasheva, T.A., Vorontsova, O.N., Bondarenko, N.A. and Seredenin, S.B. (2011) Antiparkinsonian Properties of a Nerve Growth Factor Dipeptide Mimetic GK-2 in in Vivo Experiments. Bulletin of Experimental Biology and Medicine, 151, 690-693. http://dx.doi.org/10.1007/s10517-011-1417-6

[17] Lindvall, O., Ernfors, P., Bengzon, J., Kokaia, Z., Smith, M.L., Siesjö, B.K. and Persson, H. (1992) Differential Regulation of mRNAs for Nerve Growth Factor, Brain-Derived Neurotrophic Factor, and Neurotrophin 3 in the Adult Rat Brain Following Cerebral Ischemia and Hypoglycemic Coma. Proceedings of National Academy of Sciences of the United States of America, 89, 648-652. http://dx.doi.org/10.1073/pnas.89.2.648

[18] Guégan, C., Onténiente, B., Makiura, Y., Merad-Boudia, M., Ceballos-Picot, I. and Sola, B. (1998) Reduction of Cortical Infarction and Impairment of Apoptosis in NGF-Transgenic Mice Subjected to Permanent Focal Ischemia. Molecular Brain Research, 55, 133-140. http://dx.doi.org/10.1016/S0169-328X(97)00372-0

[19] Gusev, E.I. and Skvortsova, V.I. (2001) Brain Ischemia. Medicine, Moscow.

[20] Yang, JP. Liu, H.J., Yang, H. and Fenq, P.Y. (2011) Therapeutic Time Window for the Neuroprotective Effects of NGF When Administered after Focal Cerebral Ischemia. Neurological Sciences, 32, 433-441. http://dx.doi.org/10.1007/s10072-011-0512-9

[21] Shigeno, T., Mima, T., Takakura, K., Graham, D., Kato, G., Hashimoto, Y. and Furukawa, S. (1991) Amelioration of Delayed Neuronal Death in the Hippocampus by Nerve Growth Factor. The Journal of Neuroscience, 11, 2914-2919.

[22] Zhu, W., Cheng, S., Xu, G., Ma, M., Zhou, Z., Liu, D. and Liu, X. (2011) Intranasal Nerve Growth Factor Enhances 
Striatal Neurogenesis in Adult Rats with Focal Cerebral Ischemia. Drug Delivery, 18, 338-343. http://dx.doi.org/10.3109/10717544.2011.557785

[23] Seredenin, S.B., Romanova, G.A., Gudasheva, T.A., Shakova, F.M., Barskov, I.V., Stelmashuk, E.V. and Antipova, T.A. (2011) Neuroprotective and Antiamnestic Effect of Nerve Growth Factor Dipeptide Mimetic GK-2 in Experimental Ischemic Infarction of Brain Cortex. Bulletin of Experimental Biology and Medicine, 150, 432-435. http://dx.doi.org/10.1007/s10517-011-1161-y

[24] Seredenin, S.B., Silachev, D.N., Gudasheva, T.A., Pirogov, Y.A. and Isaev, N.K. (2011) Neuroprotective Effect of GK-2, a Dipeptide Mimetic of Nerve Growth Factor, During Experimental Focal Ischemia in Middle Cerebral Artery Basin. Bulletin of Experimental Biology and Medicine, 151, 584-587. http://dx.doi.org/10.1007/s10517-011-1388-7

[25] Robinet, P.M., Rowlett, J.K. and Bardo, M.T. (1998) Individual Differences in Novelty-Induced Activity and the Rewarding Effects of Novelty and Amphetamine in Rats. Behavioural Processess, 44, 1-9. http://dx.doi.org/10.1016/S0376-6357(98)00022-9

[26] Povarnina, P.Y., Gudasheva, T.A., Vorontsova, O.N., Nikolaev, S.V., Antipova, T.A., Ostrovskaia, R.U. and Seredenin, S.B. (2012) Neuroprotective Effects of a Dipeptide Mimetic of the GK-2 Nerve Growth Factor in Model of Permanent Common Carotid Artery Occlusion in Rats. Eksperimental'naia i klinicheskaia farmakologiia, 75, 15-20.

[27] Avrushchenko, M.S., Zarzhetsky, Y.V., Moroz, V.V., Ostrova, I.V., Gudasheva, T.A. and Seredenin, S.B. (2012) Effect of Nerve Growth Factor Mimetic GK-2 on Brain Structural and Functional State in the Early Postresuccination Period. General Reanimatology, 8, 19-23.

[28] Cattaneo, A., Capsoni, S. and Paoletti, F. (2008) Towards Non Invasive Nerve Growth Factor Therapies for Alzheimer's Disease. Journal of Alzheimer's Disease, 15, 255-283.

[29] Gu, H., Long, D., Song, C. and Li, X. (2009) Recombinant Human NGF-Loaded Microspheres Promote Survival of Basal Forebrain Cholinergic Neurons and Improve Memory Impairments of Spatial Learning in the Rat Model of Alzheimer's Disease with Fimbria-Fornix Lesion. Neuroscience Letters, 453, 204-209. http://dx.doi.org/10.1016/j.neulet.2009.02.027

[30] Koliatsos, V.E., Nauta, H.J., Clatterbuck, R.E., Holtzman, D.M., Mobley, W.C. and Price, D.L. (1990) Mouse Nerve Growth Factor Prevents Degeneration of Axotomized Basal Forebrain Cholinergic Neurons in the Monkey. The Journal of Neuroscience, 10, 3801-3813.

[31] Smith, D.E., Roberts, J., Gage, F.H. and Tuszynski, M.H. (1999) Age-Associated Neuronal Atrophy Occurs in the Primate Brain and is Reversible by Growth Factor Gene Therapy. Proceedings of National Academy of Sciences of the United States of America, 96, 10893-10898. http://dx.doi.org/10.1073/pnas.96.19.10893

[32] Winkler, J. and Thal, L.J. (1995) Effects of Nerve Growth Factor Treatment on Rats Witch Lesions of the Nucleus Basalis Magnocellularis Produced by Ibotenic Acid, Quisqualic Acid, and AMPA. Experimental Neurology, 136, $234-250$. http://dx.doi.org/10.1006/exnr.1995.1100

[33] Povarnina, P.Y., Vorontsova, O.N., Gudasheva, T.A., Ostrovskaya, R.U. and Seredenin, S.B. (2013) Original Nerve Growth Factor Mimetic Dipeptide GK-2 Restores Impaired Cognitive Functions in Rat Models of Alzheimer's Disease. Acta Naturae, 5, 84-91.

[34] Polak, M., Scharfmann, R., Seilheimer, B., Eisenbarth, G., Dressler, D., Verma, I.M. and Potter, H. (1993) Nerve Growth Factor Induces Neuron-Like Differentiation of an Insulin-Secreting Pancreatic Beta Cell Line. Proceedings of National Academy of Sciences of the United States of America, 90, 5781-5781. http://dx.doi.org/10.1073/pnas.90.12.5781

[35] Rosenbaum, T., Sanches-Soto, M.C. and Hiriart, M. (2001) Nerve Growth Factor Increases Sodium Current in Pancreatic Beta-Cells. Diabetes, 50, 1755-1762. http://dx.doi.org/10.2337/diabetes.50.8.1755

[36] Nielsen, J.H., Galsgaard, E.D., Møldrup, A., Friedrichsen, B.N., Billestrup, N., Hansen, J.A., Lee, Y.C. and Carlsson, C. (2001) Regulation of Beta-Cell Mass by Hormones and Growth Factors. Diabetes, 50, S25-S29. http://dx.doi.org/10.2337/diabetes.50.2007.S25

[37] Hathway, G.J. and Fitzgerald, M. (2006) Time Course and Dose-Dependence of Nerve Growth Factor-Induced Secondary Hyperalgesia in the Mouse. The Journal of Pain, 7, 57-61. http://dx.doi.org/10.1016/j.jpain.2005.08.003 